\section{Revisionsinformation}

Version

Datum

[1]

[2015-04-27]

[2]

[2015-05-28]

$[3]$

[2015-05-28]

\section{Kommentar}

[Redovisad för styrgrupp]

[Kommentar och beslut från styrgrupp]

[Publicering]

\title{
Selektion, förvärv och tillgängliggörande av open access-resurser
}

\section{Projektets syfte}

Projektets syfte var att, parallellt med kommersiellt eller licensierat material som idag exponeras via biblioteks webbsidor och söksystem, bredda urval och exponering för att inkludera kvalitativt och relevant open access-material.

Före projektstart skedde i stort sett ingen aktiv selektion och tillgängliggörande av open access-material i form av databaser, enskilda monografier eller periodika, utan biblioteket var inriktat på att tillgängliggöra kommersiellt och licensierat material. Det upplevdes som alltmer problematiskt och gav våra användare en skev bild av utbudet. För personalen var det också motsägelsefullt att inte arbeta med open access hela vägen, från publicering till fullt tillgängliggörande via bibliotekets informationskanaler.

\section{Mål}

Projektmålen var uppdelade i två uppdragsmål, samt ett effektmål. Uppdragsmålen var att:

* identifiera förslag till bevakning, selektion, förvärv samt tillgängliggörande av kvalitativa open access-resurser

* presentera förslag på hur open access-resurser kan infogas i bibliotekets medieförsörjning, med utgångspunkt i kraven som ställs i befintliga policys. 
Effektmålet var att:

* via bibliotekets webb tillhandahålla ett väl balanserat urval av kvalitativa resurser oavsett om de är tillgängliga fritt eller kommersiellt.

Projektets målgrupp är brukare av bibliotekets informationsresurser, i första hand studenter, forskare och annan personal på Malmö högskola, i andra hand övriga användare av biblioteket. Bibliotekets personal kommer att påverkas, men dessa utgör inte i första hand projektets målgrupp.

Enligt projektplan är målen nådda, då selektion, tillgängliggörande och utvärdering av open access-material sker lika naturligt och medvetet som det gör för kommersiella resurser. En skillnad i möjligheten att utvärdera effekter internt respektive externt identifierades, där de interna bedömdes som relativt enkla att utvärdera. Externa effekter, som den större nyttan för den enskilde användaren, bedöms troligen bäst på längre sikt.

\section{Måluppfyllelse och avvikelser}

Projektet presenterar förslag på hur kvalitativt open access-material, relevant för forskning och utbildning, kan selekteras och tillgängliggöras via bibliotekets webbsidor. Projektet lyfter även att nuvarande policy för medieförsörjning samt avsiktsförklaring för tillgängliggörande av e-resurser till delar bör revideras, alternativt slås samman. Att med längre tidsperspektiv utvärdera intern och extern påverkan kan inte göras inom projekttiden, utan bör inkluderas i de utvärderingar som kontinuerligt sker av bibliotekets informationsresurser. Det gäller även eventuell påverkan på budget för medier.

\section{Projektförlopp}

Projektet arbetade från start efter en bestämd mötesagenda, och planen har till stora delar kunnat följas. Det upplevdes som en fördel att ha en relativt strikt dagordning med korta avstämningsmöten. Inte minst var det en fördel då projekttiden sammanföll med uppstarten av nya team efter biblioteket omorganisation. En nackdel för projektet var att fyra av sex medlemmar under projekttiden utsågs till teamkoordinatorer. Mot slutet av projekttiden blev därmed den tid gruppen kunde ägna åt projektet begränsad.

\section{Erfarenheter av projektprocessen}

Projektgruppens deltagare hade många gånger erfarenhet av den ena, eller den andra sidan av resurstypen - open access eller licensierade/kommersiella - men insåg fördelarna av att ha ett bredare förhållningssätt till frågan hur vi väljer och tillgängliggör resurser. Inte minst väckte frågan hur open access-resurserna "beter sig" i vårt systemlandskap intresse. 
Gruppen testade under projekttiden selektionsförfarande, effekter av aktiveringar i länkserver och discoverysystem, nedladdningar av Marc-poster för olika resurstyper, och arbetssättet blev en del av projekt- och lärandeprocessen. Gruppen kunde på så vis, strukturerat och regelbundet, följa upp och diskutera konkreta frågor. Projektet har påbörjat byggandet av en erfarenhetsbank som gör oss bättre rustade att formulera vilka krav vi ställer på open access-resurser oavsett medietyp.

Man kan se projektet som ett sätt att ge frågorna en större prioritet, vilket inte nödvändigtvis varit hjälpt av en längre projekttid. Att även efter projekttiden ha open access-frågor på agendan vid samlingsuppbyggnad och förvaltning, och att gjorda erfarenheter och goda intentioner inte avstannar blir en viktig del i det fortsatta arbetet.

\section{Organisation och ansvarsfördelning}

Projektmål, organisation eller gruppmedlemmar har inte justerats under projektets gång. Det kan bero på att tillräcklig kompetens för att nå projektmål fanns i gruppen från början, och man har därigenom inte varit beroende av kompetenser utanför gruppen. Man har också på ett självständigt sätt kunnat lägga upp arbetet efter vad gruppen bedömt som intressanta frågor, rimliga att besvara inom projekttiden.

Projektets styrgrupp bestod av bibliotekets samordningsgrupp Gunilla Lilie Bauer (Bibliotek \& IT-, samt bibliotekschef), Lotta Wogensen (enhetschef Pedagogisk verksamhet och lärandemiljö) och Peter Nilén (enhetschef Medier och vetenskaplig publicering, även uppdragsgivare)

Projektgruppen bestod av Eva Tornbjer, Ola Tengstam, Linda Trygg, Madeleine du Toit, Per Egevad och Karin Ericson Lagerås (projektledare).

\section{Styrgruppens kommentarer}

För styrgruppens kommentarer och beslut, se separat beslut daterat 2015-05-28, publicerat på http://mah.se/Om-Malmo-hogskola/Bibliotek-och-IT/Projektkontor/Pagaendeprojekt/Informationsforsorjning/

\section{Projektresultat}

Selektion av kommersiella eller licensierade resurser sker i många fall utifrån ett sammanhang eller en urvalskälla. Det kan vara ett konsortieerbjudande eller med hjälp av urvalsverktyg som Choice eller sambindningslistan från BTJ. Att open access-selektion, oavsett medietyp, upplevs som problematisk kan bero på att processerna runt urvalet blir annorlunda. Finner man däremot de rätta 
startpunkterna för urval kan arbetet få ett sammanhang och hållpunkter att utgå från då värdet och nyttan av resurserna utifrån användarens perspektiv ska diskuteras. Har man tidigt i urvalsprocessen en bild av open access-resursens större sammanhang, kan även processer som rör tillgängliggörandet i bibliotekets system underlättas.

Jämfört med Malmö högskolas open access-policy ${ }^{1}$ talar vi i detta sammanhang både om material producerat $a v$ forskare, men även om material för forskning och utbildning. Det behöver för selektionen alltså inte betyda att det bara handlar om material producerat av forskare, men däremot att det är användbart vid forskning och utbildning. Gränsen mellan vad som är open access-resurser och licensierat material är dessutom inte konstant, utan informationsresurser rör sig åt båda håll mellan de skilda formerna.

Projektets lärdomar redovisas mer i detalj i bilagan efter medietyp det vill säga periodika, monografier och övriga databaser, grupperat runt selektion respektive tillgängliggörande (se bilaga Erfarenheter av open access-selektion och tillgängliggörande). En sammanfattning av de viktigaste erfarenheterna och slutsatserna presenteras dessförinnan.

\section{Påverkan inom högskolan utom BIT, samt internt inom BIT}

Projektet har antagit att genom att lyfta open access-resurser via bibliotekets söksystem exponeras våra användare för en större mängd relevant material. Värdet och nyttan av bibliotekets webb bör då upplevas som större än tidigare. Det kommer antagligen bli svårt att säkert säga att det är så, men eventuellt kan man med en kombination av kvalitativa och kvantitativa metoder på längre sikt få en uppfattning om förhållandet. Om länkserver har ökad trafik till open accessresurser, ger även det en fingervisning om hur användarna navigerar i våra system, men en heltäckande bild är mycket svår att ge. Bibliotekets interna arbetsprocesser kan vi däremot säga kommer att påverkas direkt om open access-material ska hanteras jämsides med licensierade resurser. Ett större fokus på frågor som rör urvalskriterier vid selektion, oavsett medietyp, blir resultatet om tyngdpunkten förskjuts något från vår till stora delar användarstyrda samlingsuppbyggnad till att bibliotekets personal blir mer involverad i urval. Även hur mediebudgeten påverkas är svårt att säga, men det bör vara så att vi undviker att köpa material som faktiskt redan är fritt tillgängligt, i större utsträckning än innan. Att fortsätta dialogen med leverantörer så att de på sina plattformar markerar om en monografi, artikel eller tidskrift är open access, blir en del i det arbetet.

1

http://www.mah.se/upload/GemensamtVerksamhetsstod/dokument_mah/OA_policy 2010 11 11.pdf 


\section{Projektgruppens allmänna rekommendationer}

- Processerna runt licensierade alternativt köpta monografier och periodika är idag väl definierade inom etablerade arbetsflöden. Det är lämpligt utöka berörda arbetslags ansvarsområde, under team medier \& samlingar och team metadata, att även gälla selektion och tillgängliggörande av open access -material.

- Open access-resurser som inte kan aktiveras i länkserver och discoverysystem, eller importeras som Marc-post till katalog, behöver exponeras på annan plats. Idag är LibGuides det bästa alternativet, antingen via en ämnesguide, en databaslista eller parallellt i båda kategorier.

Gruppen menar att det behöver förtydligas var i organisationen ansvaret för denna typ av open access -resurser bör ligga. Likaså hur bästa praxis ska utarbetas för ett hållbart arbetsflöde från selektion till val av plats för exponering, kontinuerligt underhåll och utvärdering.

- Digitaliserat material som tidigare främst tillgängliggjorts som enstaka, tryckta exemplar, t ex SOU: er eller läroplaner, bör tillgängliggöras som komplett elektronisk samling via bibliotekets söksystem. Om en motsvarande gallring av tryckt material ska göras bör undersökas av team medier och samlingar.

- Policyn för medieförsörjning liksom avsiktsförklaringen för tillgängliggörande av e-resurser behöver uppdateras. Man kan överväga att slå ihop dem till ett dokument, eller fortsätta separera dem i en publik policy respektive ett internt inriktningsbeslut.

- I bilagan "Erfarenheter av open access-selektion och tillgängliggörande" presenteras förslag på upplägg av workshop för personal, med syfte att selektera open access-källor. Förslaget utgår från open access-periodika men kan användas på andra medietyper.

\section{Att tänka på vid selektion}

- OASPAs Code of Conduct ${ }^{2}$ kan tjäna som kompletterande verktyg vid selektion, vid sidan av open access -samlingar i länkserver eller andra sammanhang.

\footnotetext{
${ }^{2}$ http://oaspa.org/membership/code-of-conduct/
} 
- Man bör i en selektionsprocess göra sig en övergripande bild av en open access-samlings tillkomsthistoria, funktionalitet, övriga sammanhang och kvalitet för att få en uppfattning om i vilken mån aktivering ger tillgång fullt ut via bibliotekets söksystem.

- Att identifiera startpunkter för open access -selektion oavsett medietyp är viktigt för att ge urvalet sammanhang, och därmed även tidigt i processen identifiera hur flödet hela vägen till slutlig exponering bör se ut.

○ För selektion av främst periodika men även i någon mån monografier, är förlagsbaserade open access -samlingar i länkserver en möjlig startpunkt.

- Libris webbsök och framför allt Deldatabaserna kan fungera som startpunkt vid selektion av monografier. Det är troligt att även Swepub kan fungera som nod för urval och tillgängliggörande, även om projektet inte undersökt detta närmare.

\section{Att tänka på vid aktivering}

- Då en open access-samling aktiveras startar vi alltid i länkservern, först därefter aktiveras samlingen i discovery-tjänsten. Det är inte säkert en open access-samling finns i båda sammanhangen.

- Om en open access-samling i en länkserver saknar ISSN eller ISBN kommer länkarna inte att leda användaren vidare till materialet i något av våra söksystem. Om samlingen blir sökbar via Google scholar beror på leverantörerna.

- En open access-samling blir inte automatiskt tillgänglig om den bara aktiveras i discovery-tjänst. Detta eftersom länken inte alltid kommer att leda till resursen.

- Monografier som tillgängliggörs t ex i DOAB har många gånger andra ISBN än motsvarande titlar i aggregatorers samlingar. Det blir därför svårt att inför en aktivering eller import matcha titlarna från DOAB med innehåll på aggregatorers plattformar. Så länge open access -monografier exponeras på aggregatorers plattformar utan att det tydligt framgår att de är "födda" open access, blir det i praktiken svårt att med nuvarande rutiner utesluta dem från t ex PDA-profiler. 


\section{BILAGA}

Under rubriken "Erfarenheter av OA-selektion och tillgängliggörande" beskrivs mer i detalj projektets erfarenheter och slutsatser runt specifika frågor.

\section{Erfarenheter av OA-selektion och tillgängliggörande}

OA-monografier

Många bibliotek, både i Sverige och i andra länder, länkar till open access-material i katalog och via webben. Däremot är det ytterst oklart hur själva selektionen går till. VAD väljer andra bibliotek att exponera i sina respektive kataloger? För att ta reda på hur man gör i resten av Sverige skickade vi ut en fråga på Biblist. Vi fick in få svar, som mest var konstaterande att "det är bra att någon tar tag i de här frågorna”. Vi har också frågat några olika personer som arbetar med förvärv och/eller e-resurser på bibliotek runt om i Sverige, vilket inte heller gav några entydiga svar. Någon systematisk selektion verkar det alltså inte finnas, det som exponeras har hamnat där mer eller mindre slumpartat, åtminstone vad gäller monografier.

Vi har identifierat en del open access-monografisamlingar, som säkert kan ha relevans för oss. Några som ofta nämns är DOAB, OAPEN, Knowledge unlatched för att ta några exempel. Det finns också en del mer eller mindre färska rapporter om open access-monografier ${ }^{3}$. Information är alltså inte svårt att hitta, problemet är snarare att hitta någon form av utgångspunkt när det gäller selektion. Hur kvalitetssäkrar man det som väljs?

När det gäller exponeringen på den egna webben finns flera exempel på hur bibliotek använder LibGuides för att samla information om open accessmonografier, som komplement till sökning i kataloginnehåll.

\section{Exempel Libris webbsök, Libris Deldatabaser och Swepub}

Det finns ingen tydlig gemensam nämnare för materialet i Libris för de titlar som kan vara av intresse i detta sammanhang, men skilda sökstrategier kan tillämpas för att vaska fram det som är av intresse för oss. Söker man på ämnesord i Libris

\footnotetext{
${ }^{3}$ www.hefce.ac.uk/news/newsarchive/2015/news99909.html
}

https://oerknowledgecloud.org/sites/oerknowledgecloud.org/files/OAPEN\%20Rapport \%2 0A\%20project\%20exploring\%200pen\%20Access\%20monograph\%20publishing\%20in\%2 0the\%20Netherlands_22102013.pdf

www.kb.se/Dokument/Om/projekt/open_access/2013/A_Consortium_Approach to_OA_Bo oks_final_report_2013-08-27.pdf 
webbsök och därefter begränsar träffarna till kategori "fritt tillgängligt online", kan ett problem vara att en del titlar inte kan kallas monografier utan snarare är bokkapitel eller rapporter på endast ett fåtal sidor. Detta kan till viss del åtgärdas med att begränsa till kategori "bok". En nackdel är att vi endast vet ämne och format, men ingenting om innehållets kvalitet då vi inte alls vet vem som valt ut dessa verk eller hur de hamnat i Libris. Till skillnad från exempelvis Summon finns det i Libris webbsök ingen kategorisering som anger att posterna eller samlingarna är vetenskapligt granskade.

Att utgå från kategorin Deldatabaser kan ur den aspekten vara en bättre strategi då innehållet i dessa valts ut av personal med specialkunskaper inom respektive ämne. Man bör komma ihåg är att inte alla posterna i dessa samlingar ger tillgång till fulltexten utan måste begränsas med kategori "fritt tillgänglig online".

Ytterligare ett alternativ är att utgå från Swepub, som har ett kvalificerat innehåll av vetenskapligt granskat material. Med hjälp av ämnesord och begränsning till "fritt tillgängligt online" kan man begränsa urvalet. Vi har inte hunnit titta närmare på dessa poster inom ramen för projektet och vet därför inte tillräckligt om posternas funktionalitet för att kunna säga något om hur framkomlig denna väg för selektion och tillgängliggörande är.

Det bästa alternativet för närvarande är därför sannolikt att botanisera bland utbudet av "Deldatabaser" och se vilka som är särskilt relevanta, och därefter söka upp det bestånd i aktuell bas som är fritt tillgängligt online och har kategori "bok". Detta bestånd kan sedan göras tillgängligt i Sierra och Summon. En stor fördel med denna metod är att vi endast använder oss av deldatabaser med innehåll som valts ut av personal med specialkunskaper inom respektive ämne.

\section{Exempel Litteraturbanken}

Innehållet i Litteraturbanken är utvalt av myndigheter som får sägas ha högsta kompetens inom aktuella ämnen. Vid en snabb genomsökning kunde vi se att vi redan hade flera av titlarna i tryckt form med regelbunden utlåning. Vissa är dessutom inte längre tillgängliga att köpa i tryckt form men ständigt aktuella (Hjalmar Söderberg, Karin Boye etc.). I samlingen finns ett nämnvärt antal titlar av nu levande författare tillgängliga då Litteraturbanken förhandlat till sig rätten att lägga ut dem. Det handlar till exempel om verk av Svenska akademiens ledamöter.

Även andra bibliotek har erfarenheter av att importera Litteraturbankens bestånd till Millennium/Sierra (Göteborgs stadsbibliotek).

För att testa att tillgängliggöra Litteraturbanken i Sierra och därigenom även Summon importerades samtliga Litteraturbankens poster med kategori "bok" från 
Libris, och de redigerades på samma sätt som övriga e-böcker. Därefter gjordes ett antal felsökningar för att lokalisera fel som bland annat hänger ihop med äldre felaktiga länkar. Dessa fel korrigerades därefter i global update. Efter denna process fanns cirka 250 poster som av allt att döma fungerar som de ska i både Sierra och Summon. Därefter skapades manualer för import, nedladdning, felsökning, korrigering.

Förslagsvis genomförs denna process regelbundet enligt angivet flöde i dessa manualer, och på så sätt uppdateras ständigt vårt bestånd för Litteraturbanken.

Det är även tänkbart att på samma sätt tillgängliggöra fria böcker från deldatabaserna Dramawebben och Kvinnsam.

\section{Exempel open access-samlingar från ebrary}

I länkservern fanns vid projektstart fem open access-targets via ebrary, de var alla aktiverade sedan tidigare. Samlingarna fanns också på ebrarys sida "Free 'Open Access' Collections" http://www.ebrary.com/corp/oa.jsp. Här fanns ytterligare en samling "Library and KM Center" med ca 220 titlar.

De fem samlingarna i länkservern saknade ISBN medan "Library and KM center" hade ISBN. Samlingarna utan ISBN innehöll amerikanskt myndighetsmaterial på teman som bröstcancer, klimatförändringar, nätmobbning plus en samling texter med bibelstudier från East Texas Baptist University. Ingen av samlingarna fanns i Summon, och Marc-poster kunde inte importeras via ebrary. Sökningar i Google scholar på stickprov gav ingen träff, däremot i vanliga Google.

Samlingen "Library and KM center" verkar ingå i Academic Complete. Det framgår inte på webbsidan men titlarna är tillgängliga på plattformen och vi har tillgång till dem via katalogen. Vi har också återfunnit titlar som ingår i samlingen på EBL:s plattform, till försäljning. Exempeltiteln ${ }^{4}$ är inte open access på förlagets sida, den finns inte i OAPEN, DOAB och inte heller via Google. Däremot finns den också i Ebscos e-bokstjänst Academic Collection ${ }^{5}$.

En teori är att den enda open access-samlingen på ebrarys plattform som har ISBN är OA bara om man prenumererar på Academic Complete, alternativt om man prenumererar på Ebscos e-bokstjänst. Resonemanget kan eventuellt få stöd av att rubriken på ebrarysidan sätter open access inom citationstecken. Det är tveksamt om man då kan kalla innehållet äkta open access. En slutsats är att möjligheten att

\footnotetext{
${ }^{4}$ Subject Librarians: Engaging with the Learning and Teaching Environment, by Penny Dale, Matt Holland, and Marian Matthews (Ashgate Publishing Company, 2006)

${ }^{5}$ Enligt titellista från Ebsco nov-2014
} 
aktivera en open access-samling $\mathrm{i}$ länkserver inte automatiskt ger tillgång i våra sökgränssnitt, inte heller i Google scholar.

\section{Exempel Directory Open Access Books - Doab}

Doab innehåller omkring 2,300 titlar och samlingen fanns både i discoverysystem och i länkserver. Den aktiverades på båda platser efter modellen "se-vad-somhänder". Aktiveringen gav efter stickprovskontroll en del dubbletter och tripletter i träfflistan, likaså åt andra hållet att en titel inte exponerades alls i discovery vilket beror på att innehållet i Doab-samlingen i Summon och SFX inte matchar helt. Doab är fortfarande aktiverad i både länkserver och discoverysystemet och bevakas fortsatt för att se vad som händer med titlarnas exponering.

Från Doab kan man hämta poster via OAIPMH, även kallat OAI harvesting. Det finns möjlighet i Sierra att importera poster via OAI (användes för UR Accessposterna), men för det krävs en del förberedande arbete. Det kan vara intressant att framöver se om det finns andra databastjänster som erbjuder OAI harversting, vilket eventuellt kan innebära en enklare process att ta in poster till bibliotekssystemet.

\section{Open access-periodika}

Det finns en uppsjö open access-tidskrifter och i länkservern finns idag mer än 100 samlingar med open access-periodika och ett något mindre antal i bibliotekets discoverytjänst. Ur denna mängd är det många gånger svårt att göra sig en bild av innehåll och urvalskriterier på de ibland mycket stora samlingarna. Består samlingarna till exempel av 100 procent open access, eller är det ett blandat innehåll av open access och licensierade tidskrifter? Även förlag presenterar samlingar med utgivning av OA-tidskrifter i länkserver och discoverysystem och dessa innehåller färre tidskrifter. Man kan misstänka att dessa i större utsträckning har en genomtänkt metodik för urvalskriterierna och bör av den anledningen vara lättare att arbeta med. Förlagsbaserade open access-samlingar har många gånger också bra funktionalitet med länkning direkt till tidskriften istället för en generell förstasida som kan vara fallet med tidskrifter som tillgängliggjorts via samlingar som t ex DOAJ ${ }^{6}$.

Liksom för open access-monografier underlättas selektion av open access-periodika av att ha ett känt sammanhang, eller någon typ av erfarenhet av vad som skulle passa för användarna. En sådan erfarenhetsbank skulle förutom förlagens egna open

\footnotetext{
${ }^{6}$ Directory of Open Access Journal https://doaj.org/
} 
access-samlingar kunna bestå av de sammanhang högskolans forskare publicerat sig i, uppgifter åtkomliga för analys via högskolans publiceringssystem ${ }^{7}$.

Vilka kriterier som behöver uppfyllas är fortsatt viktigt, och då handlar det både om tidskrifters vetenskapliga meriter och om kvalitet i metadata som möjliggör en smidig process för tillgängliggörande och användning. Att selektera bör man med andra ord göra med nästa steg, tillgängliggörandet, $i$ åtanke. På så vis är det flytande gränser mellan selektion och tillgängliggörande, och det är inte alltid skarpa gränser mellan när det ena är klart och det andra tar vid.

Det har tidigare testats att aktivera open access-periodika i våra system och man fann att det oftast inte räcker att aktivera OA-tidskrifter i Summon, utan att det även krävs en aktivering av tidskrifterna i SFX för att accessen ska fungera fullt ut. Att det inte räcker att aktivera tidskrifterna enbart i Summon beror på bristande metadata.

För att open access-periodika ska vara sökbar och nåbar på artikelnivå krävs därför både aktivering i Summon (för att kunna söka upp artikeln) och i SFX (för att kunna länka till fulltexten). När projektet började testa att aktivera open accessperiodika antog vi att det eventuellt skulle räcka med att enbart aktivera tidskrifterna i Summon eftersom tidskrifterna är fritt tillgängliga och det därmed borde vara möjligt att indexera både den bibliografiska metadatan likväl som fulltexten. Men så visade sig alltså inte vara fallet.

Det finns också skillnader när det gäller länkningar i olika open access-targets i SFX. Target betyder här en samling med tidskrifter som kan vara utifrån förlag, men ibland också utifrån ämnen. Om man bara aktiverar i en target som DOAJ får man inte direktaccess till artikelnivå utan hamnar oftast på tidskriftens webbsida. Därifrån får man sedan leta sig fram till den aktuella artikeln. Men om man aktiverar open access-targets från förlag, $t$ ex Taylor Francis Open Access Free, så finns det större möjlighet att länkas direkt till artiklarna. Vid aktivering av en OAtidskrift är det därför intressant att undersöka vilka targets den finns i och välja att aktivera i den target som ger bäst länkning

\footnotetext{
${ }^{7}$ En undersökning av publiceringsmönster av forskare vid Malmö högskolas har presenterats på Mötesplats Borås 2014 och är tillgänglig på http://dspace.mah.se/bitstream/handle/2043/17910/ForskPubl_monster_2014.pdf?sequence $=2$
} 
Urvalsworkshop för OA-periodika - ett sätt att välja vad vi ska aktivera

Genom en tidskriftsworkshop kan man utifrån ett ämnesområde, med intresserade på bibliotek och fakultet, lokalisera open access-tidskrifter utifrån targets $\mathrm{i}$ länkserver. Workshop kan hållas vartannat år, förslagsvis på våren. En pilot skulle kunna ordnas inom ämnena medicin och odontologi. Nedan beskrivs ett förslag på upplägg för en sådan workshop.

\section{Förberedelseträff - mindre grupp SFX, Excel och ämneskunskap}

- Välj ut aktuella targets i SFX och hämta ut som Excelfiler.

- Lägg till sida i excelfil med länkning till bedömningsresurser, t ex Libris och Sherpa Romeo.

- Ta fram annat relevant material som MAH-publiceringar.

\section{Träff 1 med ämnesföreträdare}

- Utifrån källmaterialet kolla runt vilka OA resurser som är av intresse. Kontrollera mot Sherpa Romeo, DOAJ, OASPA, oseriösa OA-tidskrifter etc.

- Dokumentering standardiserad enligt mall för olika grupper. Resultat till träff 2

\section{Träff 2 med ämnesföreträdare (alternativt med mindre grupp?)}

- Sammanställning av resultat och beslut om aktivering

Aktiveringsprocess i första hand i länkserver och i andra hand discovery följer därefter.

Övriga typer av open access-databaser - selektion och tillgängliggörande

Sammanställningar i databasform av open access-material kan ha sitt ursprung både i open access- och i den licensierade, kommersiella världen. Det kan röra sig om digitaliserat material (till exempel Statens Offentliga Utredningar ${ }^{8}$ ), andra myndigheters utgivning ( $\mathrm{t}$ ex läroplaner ${ }^{9}$ ), eller ämnesspecifik sammanställningar (till exempel databasen Nordic Base of Early Childhood Education and Care (NBECEC $)^{10}$. Bredden av materialtyp kan också vara stor, som kartor, bilddatabaser eller rådata. Avväganden kring hur resurserna ska tillgängliggöras kan vara komplexa, allt från att importera poster till Sierra, eller att resursen inte fungerar i någon annan systemarkitektur än en databaslista, till exempel LibGuides.

Som exempel undersöktes SOU:erna från perioden 1922-1999, vilket inom kort är en komplett digitaliserad samling. Materialet är tillgängligt via Kungliga

\footnotetext{
${ }^{8} \mathrm{http}: / /$ regina.kb.se/sou/

${ }^{9}$ https://gupea.ub.gu.se/handle/2077/30490

${ }^{10} \mathrm{http} / / / \mathrm{nb}-\mathrm{ecec} . \mathrm{org} /$
} 
Bibliotekets katalog Regina där även fulltexten är enligt uppgift är sökbar ${ }^{11}$. Det digitaliserade materialet är också tillgängligt i Libris parallellt med utgivningen efter 1999.

Att se på SOU:erna som en enda komplett samling skulle kunna kallas en nygammal infallsvinkel för selektion ${ }^{12}$. Idag väljs tryckta titlar som separata exemplar, kompletterat med länk till fulltext i katalog. SOU:erna måste i stora delar anses vara en högkvalitativ resurs, även om inte hela samlingen ämnesmässigt är relevant för högskolan.

Poster kan importeras från Libris, antingen som delmängder eller som helhet, de har ämnesord och länkar till fulltexten i Regina alternativt på regeringens hemsida. Eftersom det finns en gradvis skillnad i sökfunktionaliteter i det digitaliserade materialet från Regina, posterna i Libris, eller om man befinner sig på regeringens hemsida, finns en poäng att lyfta dessa skillnader. Lämplig plats skulle vara i en ämnesövergripande databaslista.

En så pass stor samling som SOU:erna skulle ge brus i träffmängden ${ }^{13}$, men det kan vara acceptabelt eftersom man kan anta att användarna relativt ofta söker SOU: er efter utgivningsnummer, finfördelar efter utgivningsperiod eller lägger till ämnesord. Allt detta bör reducera träffmängden till acceptabla nivåer.

En följdfråga blir också om en komplett digital representation av SOU: er motiverar en 100-procentig gallring av tryckta exemplar. Projektgruppen föreslår att team medier \& samlingar undersöker frågan vidare.

För resurser där det inte finns samma möjligheter att importera poster till ILS, eller där aktivering i länkserver inte fungerar ställs andra krav på tillgängliggörande. LibGuides ger jämfört med dagens A till Z-lista möjligheter att med hjälp av egna fasta ämnesord få finare ämnesindelning men också tvåspråkighet. Det behöver inte vara ett problem att $\mathrm{i}$ en LibGuides-lista blanda kommersiella och OA-resurser så länge man med hjälp av ämnesord kan filtrera träffmängd. Man kan också skapa widgets om man vill presentera specifika resurser i databaslistan, och lyfta dessa till annan plats.

Det kommer troligen alltid att finnas diskussioner om vilka resurser som bör lyftas i en databaslista, och/eller vilka som ska lyftas i ämnesguiderna, eller vilka som inte

${ }^{11} \mathrm{http}: / / \mathrm{www} . \mathrm{kb} . \mathrm{se} / \mathrm{om} / \mathrm{verksamhet/digitalisering/Digitalisering-av-SOU/}$

${ }^{12}$ Den stående ordern av tryckta exemplar avslutades för ca 5 år sedan.

${ }^{13}$ De digitaliserade SOU:erna består av ca 5600 titlar, totalt sett finns idag i Libris drygt 7400 titlar. 
alls ska presenteras på bibliotekets webb. Idag finns inte någon given plats $\mathrm{i}$ organisationen för diskussionen eller "beställningar" runt tillgängliggörandet, och arbetet kring hur en databaslista i LibGuides skulle kunna användas är ännu i sin linda. Förutom detta kontinuerliga utvecklingsarbete behöver det förtydligas var ägandeskapet för denna kategori OA-databaser bör ligga i organisationen. Praxis för ett hållbart arbetsflöde i processen från urval, val av plats att exponera och tillgängliggöra bör undersökas mer än vad OA-projektet har kunnat göra. För att inleda och även testa ett arbetsflöde för selektion av denna typ av resurser kan man förslagsvis ordna workshops för personal, med inspiration från modellen för selektion och tillgängliggörande av OA-periodika. 